\title{
G protein, phosphorylated-GATA4 and VEGF expression in the hearts of transgenic mice overexpressing $\beta_{1}$ - and $\beta_{2}$-adrenergic receptors
}

\author{
HYUN-JIN TAE $^{1 *}$, NATALIA PETRASHEVSKAYA ${ }^{2 *}$, IN HYE KIM ${ }^{3}$, \\ JOON HA PARK ${ }^{3}$, JAE-CHUL LEE ${ }^{3}$, MOO-HO WON ${ }^{3}$, YANG HEE KIM ${ }^{4}$, JI HYEON AHN ${ }^{5}$, \\ JINSEU PARK ${ }^{5}$, SOO YOUNG $\mathrm{CHOI}^{5}$ and YONG HWAN JEON ${ }^{6}$
}

\begin{abstract}
${ }^{1}$ Bio-Safety Research Institute, College of Veterinary Medicine, Chonbuk National University, Iksan, Jeollabuk 54596, Republic of Korea; ${ }^{2}$ Cardiopulmonary Genomics Program, Departments of Medicine and Physiology, University of Maryland School of Medicine, Baltimore, MD 21201, USA; ${ }^{3}$ Department of Neurobiology, School of Medicine, Kangwon National University, Chuncheon, Gangwon 24341; ${ }^{4}$ Department of Surgery, School of Medicine, Kangwon National University, Chuncheon, Gangwon 24289; ${ }^{5}$ Department of Biomedical Science, Research Institute of Bioscience and Biotechnology, Hallym University, Chuncheon, Gangwon 24252; ${ }^{6}$ Department of Radiology, School of Medicine, Kangwon National University, Chuncheon, Gangwon 24289, Republic of Korea
\end{abstract}

Received April 28, 2016; Accepted February 22, 2017

DOI: $10.3892 / \mathrm{mmr} .2017 .6526$

\begin{abstract}
ARs) regulate cardiac contractility, calcium handling and protein phosphorylation. The present study aimed to examine the expression levels of vascular endothelial growth factor A (VEGF-A) and several $\mathrm{G}$ proteins, and the phosphorylation of transcription factor GATA binding protein 4 (GATA4), by western blot analysis, using isolated hearts from 6 month-old transgenic (TG) mice that overexpress $\beta_{1} \mathrm{AR}$ or $\beta_{2} \mathrm{AR}$. Cardiac contractility/relaxation and heart rate was increased in both $\beta_{1} \mathrm{AR}$ TG and $\beta_{2} \mathrm{AR}$ TG mouse hearts compared with wild type; however, no significant differences were observed between the $\beta_{1}$ - and $\beta_{2}$ AR TG mouse hearts. Protein expression levels of inhibitory guanine nucleotide-binding protein (Gi) 2, Gi3 and G-protein-coupled receptor kinase 2 were upregulated in both TG mice, although the upregulation of Gi2 was more prominent in the $\beta_{2} \mathrm{AR}$ TG
\end{abstract}

Correspondence to: Professor Moo-Ho Won, Department of Neurobiology, School of Medicine, Kangwon National University, 1 Gangwondaehak-gil, Chuncheon, Gangwon 24341, Repulblic of Korea

E-mail: mhwon@kangwon.ac.kr

Professor Yong Hwan Jeon, Department of Radiology, School of Medicine, Kangwon National University, 156 Baengnyeong-ro, Chuncheon, Gangwon 24289, Republic of Korea

E-mail: cjhemd@kangwon.ac.kr

*Contributed equally

Key words: $\beta_{1}$ and $\beta_{2}$ adrenergic receptors, transgenic mice, cardiomyocytes, $\mathrm{G}$ proteins, GATA4, VEGF mice. VEGF-A expression levels were also increased in both TG mice, and were highest in the $\beta_{1}$ AR TG mice. In addition, the levels of phosphorylated-GATA4 expression were increased in $\beta_{1}$ - and $\beta_{2}$ AR TG mice. In conclusion, the present study demonstrated that cardiac contractility/relaxation and heart rate is increased in $\beta_{1} \mathrm{AR}$ TG and $\beta_{2} \mathrm{AR}$ TG mice, and indicated that this increase may be related to the overexpression of $\mathrm{G}$ proteins and G-protein-associated proteins.

\section{Introduction}

Heart failure occurs when the heart is unable to maintain adequate blood circulation to meet the body's requirements, and is involved in the development of cardiac hypertrophy (1-3). Heart failure presents with an elevation of catecholamine levels, which are responsible for the functional uncoupling and downregulation of the adrenergic system $(4,5)$. The cardiomyocyte adrenergic receptor (AR) subtypes $\beta_{1}$ and $\beta_{2}$ participate in the catecholamine-mediated increase of cardiac inotropy or chronotropy (6-8). The $\beta_{1}$ - and $\beta_{2}$ ARs, which are homologous in structure, exert different effects on cardiac function (9); these differences may be explained by the distinct G-protein couplings associated with the $\beta A R$ subtype (10). In particular, $\beta_{2} \mathrm{AR}$ activates stimulatory guanine nucleotide-binding proteins (Gs) and pertussis toxin-sensitive inhibitory guanine nucleotide-binding protein (Gi) 2 and Gi3 signaling pathways, whereas $\beta_{1} \mathrm{AR}$ exclusively couples to the Gs/adenylyl cyclase/cyclic AMP (cAMP)/protein kinase A (PKA) signaling cascade (11). However, the differing underlying mechanisms between $\beta_{1} \mathrm{AR}$ and $\beta_{2} \mathrm{AR}$ remain unknown.

Notably, the vascular endothelial growth factor (VEGF) family has been revealed to exhibit an ability to initiate angiogenic cascades in the absence of ischemia or inflammation $(12,13)$. Furthermore, $\beta_{1^{-}}$and $\beta_{2}$ ARs were demonstrated 
to mediate norepinephrine-induced VEGF upregulation (12). Important roles for VEGF-A have been suggested in the cardiovascular system, including angiogenesis and vasodilation (13). The transcription factor GATA4 has been reported to directly regulate VEGF expression, via binding to the promoter of the VEGF-A gene; GATA4 has been suggested to function as a stress-response regulator, by coordinating angiogenetic processes following hemodynamic load, through the modulation of non-hypoxic and load-responsive mechanisms (14). However, it is currently unclear whether distinct $\beta_{1}$ - and $\beta_{2}$ AR-mediated signaling mechanisms are involved in VEGF-A regulation in hemodynamically challenged hearts. The molecular mechanisms underlying the differences between $\beta_{1}$ - and $\beta_{2} \mathrm{AR}$ signaling remain largely unknown. Therefore, the present study aimed to compare the expression of Gs, VEGF-A and their associated proteins, in hearts from $\beta_{1}$ AR transgenic (TG), $\beta_{2}$ AR TG and wild-type (WT) mice.

\section{Materials and methods}

TG mice. The generation of $\beta_{1} \mathrm{AR}$ and $\beta_{2} \mathrm{AR}$ TG mice that overexpress human cardiac-specific $\beta_{1}$ - or $\beta_{2}$ ARs was performed as previously described (6,7). In brief, wild-type human $\beta_{1}$ and $\beta_{2}$-AR cDNA was ligated into the SalI site (exon 3 ) of the full-length 5.5-kb $\alpha$-myosin heavy chain (MHC) promoter, obtained from Dr. Arthur R. Struch, (Mayo Clinic, Rochester, MN, USA). The linearized constructs were injected into male pronuclei of fertilized FVB/N mouse oocytes and implanted into pseudopregnant female oviducts (Taconic Biosciences, Rensselaer, NY, USA). Genomic DNA from tail-cuts was screened for the presence of transgenes, using targeted PCR with the following primers: For $\beta_{1} \mathrm{AR}$, forward primer 5'-AGG ACT TCA CAT AGA AGC CTA G-3', located in the $\alpha$-MHC promoter, and reverse primer 5'-TGT CCA CTG CTG AGA CAG CG-3', located in the $\beta_{1} \mathrm{AR}$ coding sequence. For $\beta_{2} \mathrm{AR}$, forward primer 5'-GGAGCAGAGTGGATATCACG-3', located in the open reading frame, and reverse primer 5'-GTC ACACCACAGAAGTAAGG-3', located in the SV40 polyadenylation region. A total of 39 male mice $(n=13$ mice/group) were housed in individual cages (temperature, $23^{\circ} \mathrm{C}$; humidity, $60 \%$ ) under $12 / 12 \mathrm{~h}$ light/dark cycles, and provided with commercial chow and water ad libitum. Mice were examined at 6 months of age, to ensure the presented phenotypes were independent of the confounding effects of cardiac growth and associated alterations to $\beta$ AR functional coupling. Animal procedures were approved by the University of Maryland Baltimore Institutional Animal Care and Use Committee.

Physiological parameters. Physiological parameters were evaluated in an isolated work-performing experiment, according to a previously published procedure (7). Briefly, mice ( $\mathrm{n}=5$ /group; age, 6 months; weight, $\sim 35 \mathrm{~g}$ ) were anesthetized via intraperitoneal injection of $100 \mathrm{mg} / \mathrm{kg}$ Nembutal and 1.5 units of heparin to prevent microthrombosis, the heart and aorta were attached to a 20-gauge cannula and subjected to temporary retrograde perfusion with oxygenated Krebs-Henseleit solution $(118 \mathrm{mM}$ $\mathrm{NaCl}, 4.7 \mathrm{mM} \mathrm{KCl}, 2.5 \mathrm{mM} \mathrm{CaCl} 2,0.5 \mathrm{mM}$ Na-EDTA, $25 \mathrm{mM}$ $\mathrm{NaHCO}_{3}, 1.2 \mathrm{mM} \mathrm{KH} \mathrm{PO}_{4}, 11 \mathrm{mM}$ glucose; followed by saturation with $95 \% \mathrm{O}_{2}+5 \% \mathrm{CO}_{2}$ ). A polyethelene-50 catheter was inserted into the apex of the left ventricle to measure intraventricular pressure. The pulmonary vein was connected to a second cannula and the antegrade perfusion was initiated with a basal workload of $300 \mathrm{mmHg} \mathrm{ml} / \mathrm{min}$ (venous return, $6 \mathrm{ml}$; mean aortic pressure, $50 \mathrm{mmHg}$ ). Hearts were allowed to equilibrate for $20 \mathrm{~min}$. Atrial pressure was monitored through a sidearm in the left atrial cannula (National Instruments Corporation, Austin, Texas, US). The left ventricular pressure signals were analyzed off-line using NI Biobench software version 1.0 (National Instruments Corporation). The first positive and negative derivatives of the left intraventricular pressure curve [that is, the maximal rate pressure development $(+\mathrm{dP} / \mathrm{dt})$ and the maximal rate pressure decline $(-\mathrm{dP} / \mathrm{dt})]$, the duration of contraction and relaxation [that is, time to peak pressure (TPP)], and the time to half relaxation ( $\mathrm{TR}^{1 / 2}$ ) were calculated. TPP was normalized with respect to peak systolic pressure, calculated as: Systolic pressure-end diastolic pressure. TR $1 \frac{2}{2}$ was normalized with respect to $1 / 2$ relaxation pressure, calculated as: (Systolic pressure-diastolic pressure)/2.

Hematoxylin and eosin (H\&E) staining. Mice (n=5/group) were anesthetized via intraperitoneal injection of pentobarbital sodium $(100 \mathrm{mg} / \mathrm{kg})$. Hearts were isolated and fixed with $10 \%$ buffered formalin for 2 days at room temperature. The heart/body weight ratio was calculated according to the following formula: Heart/body weight ratio=heart weight (mg)/body weight $(\mathrm{g})$. Hearts were embedded in paraffin and sectioned $(6 \mu \mathrm{m})$. The sections were stained with H\&E, and digital images were captured using a light microscope and analyzed using the digital imaging analysis software Leica Steel Expert version 2.0 (Leica Microsystems GmbH, Wetzlar, Germany). Cardiomyocyte diameter was determined as the shortest distance across the nucleus in transverse cell sections. Cardiomyocytes $(n=100)$ from 5 randomly selected microscope fields (x200 magnification) from the posterior wall of the left ventricle were measured to represent the average cardiomyocyte diameter.

Western blotting. The expression of heart proteins was detected according to previously published procedures (15). Briefly, proteins were extracted from heart tissue ( $\sim 50 \mathrm{mg}$ tissue; $\mathrm{n}=3$ mice/group) using radioimmunoprecipitation assay buffer (1:4 w:v; R2002, Biosesang, Inc., Soungnam, Korea) containing $150 \mathrm{mM} \mathrm{NaCl}, 1 \%$ Triton X-100, $1 \%$ sodium deooxycholate, $50 \mathrm{mM}$ Tris $\mathrm{HCl}$ (pH 7.5), $0.1 \%$ SDS, 2 mM EDTA (pH 8.0) and phosphatase inhibitor cocktail for $10 \mathrm{~min}$ over ice. Lysates were centrifuged at $19,000 \times \mathrm{g}$ for $10 \mathrm{~min}$ at $4^{\circ} \mathrm{C}$ and supernatants were collected. Protein concentrations were determined using a bicinchoninic acid assay kit. Equal amounts of extracted protein samples $(200 \mathrm{mg} / \mathrm{ml})$ were subjected to Tris-Glycine-SDS PAGE, transferred onto polyvinylidene fluoride membranes. Membranes were blocked with 5\% non-fat skim milk in TBS containing $0.1 \%$ Tween 20 for $2 \mathrm{~h}$ at room temperature and probed with the following primary antibodies overnight at $4^{\circ} \mathrm{C}$ : Anti-Gs (1:500; cat no. sc26766), anti-Gi2 (1:500; cat no. sc391), anti-Gi3 (1:500; cat no. sc262), anti-G-protein-coupled receptor kinase 2 (GRK2; 1:500; cat no. sc562), anti-GATA binding protein 4 (GATA4; 1:1,000; cat no. sc1237) and anti-GAPDH (1:2,000; cat no. sc166574), obtained from Santa Cruz Biotechnology, Inc. (Dallas, TX, USA); anti-VEGF-A (1:1,000; cat no. ab1316) and anti-phosphorylated (p)-GATA4 (1:500; cat 
no. ab5245) obtained from Abcam (Cambridge, MA, USA) Membranes were then incubated with goat anti-rabbit horseradish peroxidase-conjugated secondary antibodies (1:5,000; cat no. SC-2004; Santa Cruz Biotechnology, Inc., Dallas, TX, USA) for $2 \mathrm{~h}$ at room temperature. Protein bands were visualized using Amersham ECL Western Blotting Detection Reagent (GE Healthcare Life Sciences, Chalfont, UK) and the signals were acquired using a LAS-3000 charged coupled device camera (Fujifilm Holdings Corporation, Tokyo, Japan). Blots were semi-quantified using densitometric analysis and protein expression was normalized to GAPDH. Semi-quantification was performed using the Scion Image software version 4.0.3.2 (Scion Corporation, Walkersville, MD, USA). Experiments were performed in triplicate.

Statistical analysis. All data are presented as the mean \pm standard error of the mean. Differences of the means amongst the groups were estimated by one-way analysis of variance followed by a post hoc Bonferroni test for multiple comparisons. All analyses were performed using SPSS version 20.0 (IBM SPSS, Armonk, NY, USA). P<0.05 was considered to indicate a statistically significant difference.

\section{Results}

Physiological parameters. The cardiac function of $\beta_{1} \mathrm{AR}$ TG and $\beta_{2}$ AR TG mice was enhanced, and the cardiac contractility/relaxation and heart rate of $\beta_{1}$ - and $\beta_{2} \mathrm{AR}$ TG mice were significantly increased compared with the WT mice (Table I). No significant differences between the $\beta_{1} \mathrm{AR}$ and $\beta_{2} \mathrm{AR}$ TG mouse hearts were identified; however, the clinical parameters, including left ventricular systolic pressure (SP), left ventricular diastolic pressure (DP), left ventricular end-diastolic pressure (EDP) and TPP in $\beta 2 \mathrm{AR}$ TG mice appeared to be slightly increased compared with in $\beta 1 \mathrm{AR}$ TG mice.

Myocardial hypertrophy. Heart/body weight ratio was significantly greater in $\beta_{1} \mathrm{AR}$ and $\beta_{2} \mathrm{AR}$ TG mice compared with in WT mice $(3.91 \pm 0.07$ and $3.78 \pm 0.06 \mathrm{mg} / \mathrm{g}$ vs. $3.61 \pm 0.03 \mathrm{mg} / \mathrm{g}$, respectively; $\mathrm{P}<0.05$ ); however, no statistical significance was identified between the two transgenic groups. The diameter of the cardiomyocytes demonstrated a similar trend to the heart/body weight ratios; cell diameters were greater in $\beta A R$ TG mice compared with in the WT mice, however, no significant differences in cardiomyocyte size were detected between the two transgenic groups (Fig. 1).

Expression levels of $G$ proteins and GRK2. Protein expression levels of GRK2, Gs, Gi2 and Gi3 were examined by western blot analysis (Fig. 2). Gs protein expression level was significantly decreased, whereas Gi2, Gi3 and GRK2 expressions were significantly increased, in $\beta_{1} \mathrm{AR}$ and $\beta_{2} \mathrm{AR}$ TG mice compared with WT mice (Fig. 2). The upregulation of Gi2 was greatest in the $\beta_{2} \mathrm{AR}$ TG mice compared with the other two groups.

Expression levels of VEGF-A and GATA4. Upregulation of VEGF-A expression was detected in both $\beta_{1}$ AR and $\beta_{2}$ AR TG mice; however, the $\beta_{2}$ AR TG mice exhibited a smaller increase compared with $\beta_{1}$ AR TG mice. Furthermore, GATA4 serine
105 phosphorylation (p-GATA4) was similarly increased in both $\beta_{1}$ and $\beta_{2}$ AR TG mice, compared with the WT group. Phosphorylation on serine 105 is an event known to augment GATA4 activity. No significant difference in pGATA4 expression was observed between the $\beta_{1} \mathrm{AR}$ and $\beta_{2} \mathrm{AR}$ TG mice (Fig. 3).

\section{Discussion}

The present study examined physiological parameters in an isolated work-performing heart experiment of $\beta_{1} \mathrm{AR}$ TG and $\beta_{2}$ AR TG mice. The results indicated that cardiac contractility/relaxation and heart rate were stronger in the $\beta_{2} A R$ TG mice, compared with the $\beta_{1} \mathrm{AR}$ TG mice; however, this difference was not significant. The reduced hemodynamic functional response in the $\beta_{1} \mathrm{AR}$ TG mouse heart may reduce cardiac cellular stress and metabolic expenditure.

The diameter of the cardiomyocytes was greater in the $\beta A R$ TG mice compared with the WT mice, indicating the presence of hypertrophy. Previous studies reported that $\beta A R$ signaling induces cardiomyocyte apoptosis through a Gs-mediated PKA-dependent mechanism (16-18), and $\beta_{1^{-}}$and $\beta_{2}$ AR may exert different effects on cardiac apoptosis $(19,20)$, which may be due to the distinct G-protein couplings of $\beta A R$ subtypes (11). In the present study, GRK2, Gi2 and Gi3 protein expression levels were significantly increased, whereas Gs expression levels were significantly decreased in $\beta_{1} A R$ and $\beta_{2}$ AR TG mice compared with WT. Furthermore, Gi2 expression was significantly higher in the $\beta_{2} \mathrm{AR}$ TG mice, compared with the $\beta_{1} \mathrm{AR}$ TG mice. Foerster et al (21) reported that, unlike $\beta_{1} \mathrm{AR}$, the effects of $\beta_{2} \mathrm{AR}$ overexpression varied at the level of $\mathrm{Gi} 2$ and $\mathrm{Gi} 3$ proteins; $\beta_{2} \mathrm{AR}$ was associated with more prominent Gi2 upregulation and suggested that Gi2 may contribute to a longer survival and delayed cardiac pathology in $\beta_{2} \mathrm{AR}$ TG mice. Furthermore, Gi2 upregulation may reduce the deleterious effects of catecholamine signaling, contribute to several protective aspects ascribed to $\beta_{2} \mathrm{AR} / \mathrm{Gi}$ coupling and reduce cardiac responsiveness against a number of Gaq-protein-related pro-growth factors (22). Based on these data, it may be hypothesized that the coupling of $\beta_{2} \mathrm{AR}$ and Gi may provide negative feedback to the $\beta_{2} \mathrm{AR} / \mathrm{Gs}$-mediated cAMP signal, thus resulting in reduced cardiac inotropy.

Previous research has indicated that the declined hemodynamic response in the $\beta_{2} \mathrm{AR}$ TG mouse heart would result in reduced capillary growth (23). Furthermore, it has been suggested that regulatory circuits might exist between catecholamine-induced inotropy and VEGF expression in the heart, which adjusts hemodynamic load to myocardial blood supply (12). Heineke et al demonstrated that GATA4 directly regulates VEGF expression by binding to the VEGF-A gene promoter and functions as a stress-responsive regulator that coordinates angiogenesis following alterations to hemodynamic load via non-hypoxic and load-responsive mechanisms (14). Based upon these findings, the present study examined the expression levels of GATA4 and VEGF-A in both $\beta A R$ TG mouse hearts. Although cardiac contractility/relaxation and heart rate were similarly increased in $\beta_{1}$ and $\beta_{2} \mathrm{AR}$ TG mice, VEGF-A protein expression levels were significantly upregulated in myocardial tissue isolated from $\beta_{1}$ AR TG mice compared with in tissue from $\beta_{2} \mathrm{AR}$ TG 
Table I. Physiological parameters in the isolated work-performing hearts of the WT, $\beta_{1} \mathrm{AR}$ TG and $\beta_{2} \mathrm{AR}$ TG mice.

\begin{tabular}{lcrr}
\hline Physiological parameter & WT & $\beta_{1}$ AR TG & $\beta_{2}$ AR TG \\
\hline Heart/body weight ratio (mg/g) & $3.61 \pm 0.03$ & $3.91 \pm 0.07^{\mathrm{a}}$ & $3.78 \pm 0.06^{\mathrm{a}}$ \\
SP (mmHg) & $133.4 \pm 1.7$ & $159.4 \pm 3.5^{\mathrm{a}}$ & $168.1 \pm 4.8^{\mathrm{a}}$ \\
DP (mmHg) & $-8.1 \pm 1.36$ & $-33.7 \pm 1.3^{\mathrm{a}}$ & $-37.7 \pm 3.4^{\mathrm{a}}$ \\
EDP (mmHg) & $7.7 \pm 0.9$ & $2.1 \pm 0.5^{\mathrm{a}}$ & $3.9 \pm 0.8^{\mathrm{a}}$ \\
+dP/dt (mmHg/s) & $3961 \pm 41$ & $5927 \pm 187^{\mathrm{a}}$ & $5775 \pm 342^{\mathrm{a}}$ \\
dP/dt (mmHg/s) & $2763 \pm 130$ & $5179 \pm 206^{\mathrm{a}}$ & $5270 \pm 156^{\mathrm{a}}$ \\
HR (beats/minute) & $247 \pm 3.9$ & $334 \pm 4.3^{\mathrm{a}}$ & $316 \pm 0.9^{\mathrm{a}}$ \\
TPP (msec/mmHg) & $0.40 \pm 0.01$ & $0.25 \pm 0.02^{\mathrm{a}}$ & $0.31 \pm 0.03^{\mathrm{a}}$ \\
TR $1 / 2(\mathrm{msec} / \mathrm{mmHg})$ & $0.63 \pm 0.02$ & $0.40 \pm 0.03^{\mathrm{a}}$ & $0.47 \pm 0.03^{\mathrm{a}}$
\end{tabular}

${ }^{\mathrm{a}} \mathrm{P}<0.05$ vs. WT. Data are expressed as the mean \pm standard error of the mean. $\mathrm{N}=5$ mice/group. $+\mathrm{dP} / \mathrm{dt}$, maximal rate pressure development; $-\mathrm{dP} / \mathrm{dt}$, maximal rate pressure decline; AR, adrenergic receptor; DP, left ventricular diastolic pressure; EDP, left ventricular end-diastolic pressure; HR, heart rate; SP, left ventricular systolic pressure; TG, transgenic receptor; TPP, time to peak pressure (normalized to peak pressure); TR $1 / 2,1 / 2$ relaxation pressure (normalized to $1 / 2$ relaxation pressure); WT, wild type.

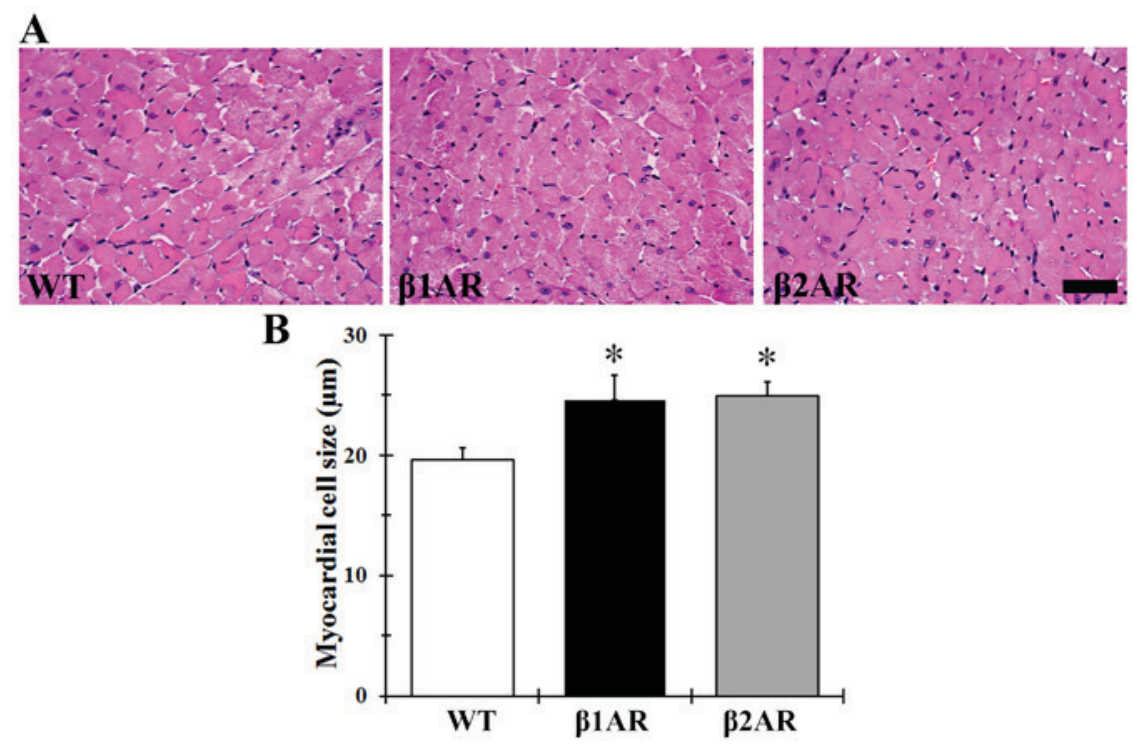

Figure 1. H\&E staining and measurement of cardiomyocyte size in WT, $\beta_{1} \mathrm{AR}$ TG and $\beta_{2} \mathrm{AR}$ TG mice. (A) H\&E staining revealed ventricular cardiomyocyte hypertrophy in both $\beta$ AR TG mice. Scale bar, $50 \mu \mathrm{m}$. (B) Quantification of cardiomyocyte size in the transverse section in WT, $\beta_{1}$ - and $\beta_{2}$ AR TG mice. Data represent the shortest cardiomyocyte diameter through the nucleus. The results are presented as mean \pm standard error of the mean. "P<0.05 vs. WT mice. AR, adrenergic receptor; H\&E, hematoxylin and eosin; TG, transgenic; WT, wild type.
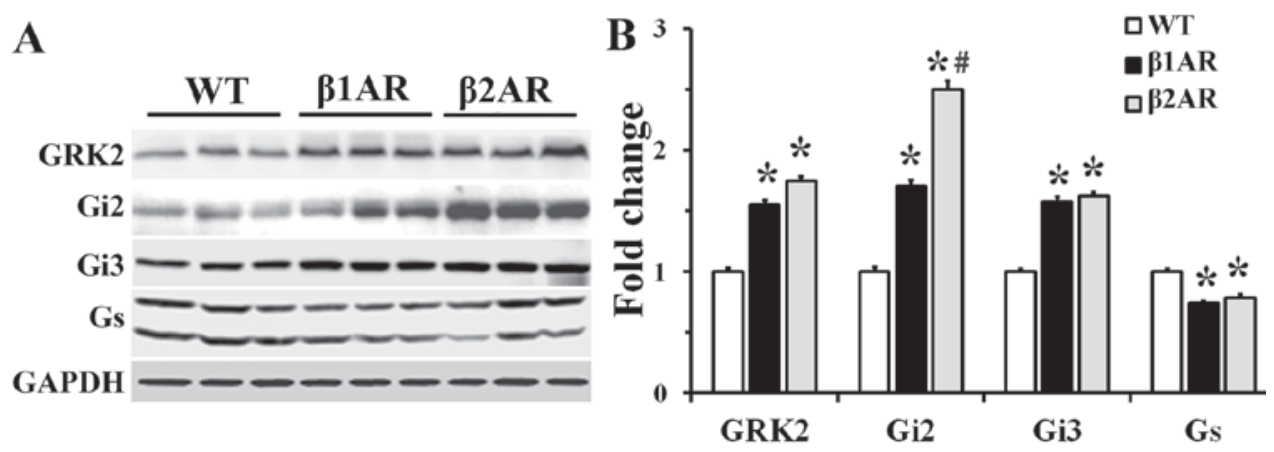

Figure 2. GRK2, Gi2, Gi3 and Gs protein expression in cardiac homogenates from WT, $\beta_{1}$ AR TG and $\beta_{2}$ AR TG mouse hearts. (A) Western blot analysis of GRK2, Gi2, Gi3 and Gs. (B) Quantification of western blot analysis; protein expressions are normalized to GAPDH. Values are the mean \pm standard error of the mean. $\mathrm{N}=3$ mice/group. " $\mathrm{P}<0.05$, vs. WT mice. ${ }^{\prime \prime} \mathrm{P}<0.05$ vs. $\beta_{1} \mathrm{AR}$ TG mice. AR, adrenergic receptor; Gi, inhibitory guanine nucleotide-binding protein; GRK2, G-protein coupled receptor kinase 2; Gs, stimulatory guanine nucleotide-binding protein; TG, transgenic; WT, wild type. 


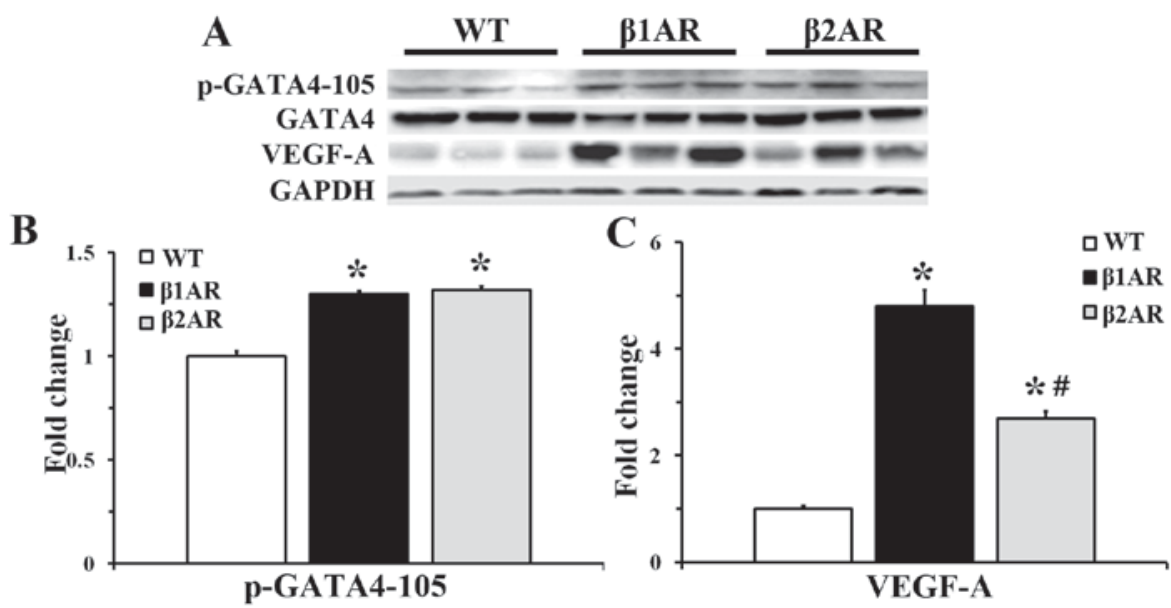

Figure 3. GATA4 and VEGF-A protein expression in WT, $\beta_{1}$ AR TG and $\beta_{2}$ AR TG mice. (A) Western blot analysis of heart protein extracts for p-GATA4-105, total GATA4 and VEGF-A. (B and C) Densitometric quantification of western blot analysis. Values are the mean \pm standard error of the mean. N=3 mice/group; "P<0.05 vs. WT; ${ }^{*} \mathrm{P}<0.05$ vs. $\beta_{1}$ AR TG mice. AR, adrenergic receptor; GATA4, GATA binding protein 4; p-GATA4-105, GATA4 protein phosphorylated on serine 105; TG, transgenic; VEGF-A, vascular endothelial growth factor A; WT, wild type.

mice. In addition, p-GATA4 protein expression was similarly increased in myocardial samples from $\beta_{1}$ and $\beta_{2} \mathrm{AR}$ TG mice.

Therefore, the present study hypothesized that VEGF-A-induced variation in angiogenesis may be associated with one of the mechanisms that halts hypertrophic remodeling of the heart in the $\beta_{2} \mathrm{AR}$ TG mice. Notably, Tirziu et al (13) reported that increased endothelial cell mass and endothelial cell-cardiomyocyte interactions stimulated hypertrophic growth, via releasing paracrine factors, such as VEGF, from the vascular endothelium.

In conclusion, the present study demonstrated that cardiac contractility/relaxation and heart rate was increased in $\beta_{1} \mathrm{AR}$ and $\beta_{2} \mathrm{AR}$ TG mice, and that these increases may be due to $\beta_{2} \mathrm{AR}$-mediated upregulation of $\mathrm{Gi}$ protein expression and reduced upregulation of VEGF-A, in comparison with $\beta_{1} A R$ TG mice.

\section{Acknowledgements}

The authors would like to thank Mr Seung Uk Lee (Department of Neurobiology, School of Medicine, Kangwon National University, Chuncheon, Republic of Korea) for his technical help in this study. The present study was supported by the Basic Science Research Program through the National Research Foundation of Korea (NRF), the Ministry of Education (grant no. NRF-2014R1A1A2057263), the Priority Research Centers Program (grant no. NRF-2009-0093812), the National Research Foundation of Korea, the Ministry of Science, ICT \& Future Planning and the National Institutes of Health (grant no. HL077101).

\section{References}

1. Cao S, Zeng Z, Wang X, Bin J, Xu D and Liao Y: Pravastatin slows the progression of heart failure by inhibiting the c-Jun $\mathrm{N}$-terminal kinase-mediated intrinsic apoptotic signaling pathway. Mol Med Rep 8: 1163-1168, 2013.

2. Sun JM, Wang CM, Guo Z, Hao YY, Xie YJ, Gu J and Wang AL: Reduction of isoproterenol-induced cardiac hypertrophy and modulation of myocardial connexin 43 by a KATP channel agonist. Mol Med Rep 11: 1845-1850, 2015.
3. Wang N, Cao Y and Zhu Y: Netrin-1 prevents the development of cardiac hypertrophy and heart failure. Mol Med Rep 13: 2175-2181, 2016.

4. Pereira SB, Velloso MW, Chermont S, Quintão MM, Nunes Abdhala R, Giro C, Oliveira E Alves T, Camacho V, De Fátima Maia Contarato L, Pena FM, et al: $\beta$-adrenergic receptor polymorphisms in susceptibility, response to treatment and prognosis in heart failure: Implication of ethnicity. Mol Med Rep 7: 259-265, 2013.

5. Yu J, Yang S, Wang X and Gan R: Matrine improved the function of heart failure in rats via inhibiting apoptosis and blocking $\beta 3$ adrenoreceptor/endothelial nitric oxide synthase pathway. Mol Med Rep 10: 3199-3204, 2014.

6. Liggett SB, Tepe NM, Lorenz JN, Canning AM, Jantz TD Mitarai S, Yatani A and Dorn GW II: Early and delayed consequences of beta(2)-adrenergic receptor overexpression in mouse hearts: Critical role for expression level. Circulation 101: 1707-1714, 2000.

7. Mialet Perez J, Rathz DA, Petrashevskaya NN, Hahn HS, Wagoner LE, Schwartz A, Dorn GW, Liggett SB, et al: Beta 1-adrenergic receptor polymorphisms confer differential function and predisposition to heart failure. Nat Med 9: 1300-1305, 2003.

8. Xiao RP, Zhu W, Zheng M, Chakir K, Bond R, Lakatta EG and Cheng H: Subtype-specific beta-adrenoceptor signaling pathways in the heart and their potential clinical implications. Trends Pharmacol Sci 25: 358-365, 2004.

9. Zaugg M, Xu W, Lucchinetti E, Shafiq SA, Jamali NZ and Siddiqui MA: Beta-adrenergic receptor subtypes differentially affect apoptosis in adult rat ventricular myocytes. Circulation 102: 344-350, 2000

10. Xiao RP, Cheng H, Zhou YY, Kuschel M and Lakatta EG: Recent advances in cardiac beta(2)-adrenergic signal transduction. Circ Res 85: 1092-1100, 1999.

11. Hanft LM and McDonald KS: Sarcomere length dependence of power output is increased after PKA treatment in rat cardiac myocytes. Am J Physiol Heart Circ Physiol 296: H1524-H1531, 2009.

12. Fredriksson JM, Lindquist JM, Bronnikov GE and Nedergaard J: Norepinephrine induces vascular endothelial growth factor gene expression in brown adipocytes through a beta-adrenoreceptor/cAMP/protein kinase a pathway involving src but independently of Erk1/2. J Biol Chem 275: 13802-13811, 2000.

13. Tirziu D, Chorianopoulos E, Moodie KL, Palac RT, Zhuang ZW, Tjwa M, Roncal C, Eriksson U, Fu Q, Elfenbein A, et al: Myocardial hypertrophy in the absence of external stimuli is induced by angiogenesis in mice. J Clin Invest 117: 3188-3197, 2007.

14. Heineke J, Auger-Messier M, Xu J, Oka T, Sargent MA, York A, Klevitsky R, Vaikunth S, Duncan SA, Aronow BJ, et al: Cardiomyocyte GATA4 functions as a stress-responsive regulator of angiogenesis in the murine heart. J Clin Invest 117: 3198-3210, 2007 
15. Lee JC, Kim IH, Cho GS, Park JH, Ahn JH, Yan BC, Kwon HM, $\mathrm{Kim} \mathrm{YM}$, Cheon $\mathrm{SH}$, Cho JH, et al: Ischemic preconditioning-induced neuroprotection against transient cerebral ischemic damage via attenuating ubiquitin aggregation. J Neurol Sci 336: 74-82, 2014

16. Dorn GW II, Tepe NM, Lorenz JN, Koch WJ and Liggett SB: Low- and high-level transgenic expression of beta2-adrenergic receptors differentially affect cardiac hypertrophy and function in Galphaq-overexpressing mice. Proc Natl Acad Sci USA 96: 6400-6405, 1999.

17. Du XJ, Autelitano DJ, Dilley RJ, Wang B, Dart AM and Woodcock EA: beta(2)-adrenergic receptor overexpression exacerbates development of heart failure after aortic stenosis. Circulation 101: 71-77, 2000.

18. Du XJ, Gao XM, Jennings GL, Dart AM and Woodcock EA: Preserved ventricular contractility in infarcted mouse heart overexpressing beta (2)-adrenergic receptors. Am J Physiol Heart Circ Physiol 279: H2456-H2463, 2000.

19. Endoh M: Force-frequency relationship in intact mammalian ventricular myocardium: Physiological and pathophysiological relevance. Eur J Pharmacol 500: 73-86, 2004.
20. Engelhardt S, Hein L, Dyachenkow V, Kranias EG, Isenberg G and Lohse MJ: Altered calcium handling is critically involved in the cardiotoxic effects of chronic beta-adrenergic stimulation. Circulation 109: 1154-1160, 2004.

21. Foerster K, Groner F, Matthes J, Koch WJ, Birnbaumer L and Herzig S: Cardioprotection specific for the $\mathrm{G}$ protein $\mathrm{Gi} 2$ in chronic adrenergic signaling through beta 2 -adrenoceptors. Proc Natl Acad Sci USA 100: 14475-14480, 2003.

22. Petrashevskaya N, Gaume BR, Mihlbachler KA, Dorn GW II and Liggett SB: Bitransgenesis with beta(2)-adrenergic receptors or adenylyl cyclase fails to improve beta(1)-adrenergic receptor cardiomyopathy. Clin Transl Sci 1: 221-227, 2008.

23. Xu Q, Jennings NL, Sim K, Chang L, Gao XM, Kiriazis H, Lee YY, Nguyen MN, Woodcock EA, Zhang YY, et al: Pathological hypertrophy reverses $\beta 2$-adrenergic receptor-induced angiogenesis in mouse heart. Physiol Rep 3: pii: e12340, 2015. 